\title{
Prices, Abbreviations, and Hours
}
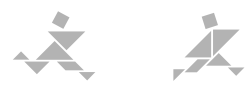

Exact prices are not included in this edition since they change so quickly from year to year. In addition, a large number of listings have a single fee covering multiple class sessions, or charge a camp or semester tuition. In many instances, a facility may have different course fees for different classes, and courses change from semester to semester as well. For this reason, any price information would be quickly out of date, so they are not given for those entries.

For listings that do have a simple entrance fee, however, the range of prices is indicated by the following codes:

$$
\begin{aligned}
\$ & =\text { up to } \$ 5 \\
\$ \$ & =\$ 5 . \text { OI to } \$ \text { IO } \\
\$ \$ \$ & =\$ \text { IO.OI to } \$ \text { I5 } \\
\$ \$ \$ \$ & =\$ \text { I5.OI to } \$ 25 \\
\$ \$ \$ \$ & =\$ 25 . \text { OI to } \$ 35 \\
\$ \$ \$ \$ \$ & =\$ 35 . \text { OI and above }
\end{aligned}
$$

\section{ABBREVIATIONS}

(BP) = Birthday Parties (including other themed parties)

ङ = Summer Camp (typically day camps as well as other summer programs)

\section{HOURS}

Because classes often list numerous times, the hours provided are often general, such as "after-school and Saturdays." When a facility is seasonal, the months or seasons are listed. While the hours of operation were accurate when this edition went to press, they can change at any time-and often do. So, too, do the names and content of classes and special programs and events. Readers are strongly encouraged to check a listing's website and to telephone first. 

New Jersey for Kids

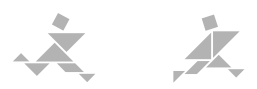


